\title{
Operations Research Model Formulation for Road Maintenance Case
}

\author{
Jānis Pekša ${ }^{1}$, Kristaps-Pēteris Rubulis ${ }^{2}$ \\ ${ }^{1,2}$ Riga Technical University, Riga, Latvia
}

\begin{abstract}
Operations research can be used to apply analytical methods that help make precise and reasonable decisions. In road maintenance, basic principles of operations research are used to create model formulation that could help lower costs in case of an inaccurately made decision. First, the paper provides a literature review on different model formulations. Afterward, hypotheses are proposed regarding the model formulation, and then the model that minimises total generalised costs from wrong duty orders for road maintenance is offered. In conclusion, the paper evaluates the hypotheses and the process of improving the mathematical model.
\end{abstract}

Keywords - Model formulation, operations research, road maintenance.

\section{INTRODUCTION}

Road maintenances works are very diverse and specific, ranging from laying of the road surface to daily maintenance activities. Many stakeholders, including managers, dispatchers, and maintenance teams are involved, and maintenance decisions need to be made promptly [1]. Proactive maintenance activities are enabled by forecasting. Forecasting provides advance information about the required maintenance activities. The anti-slip maintenance is performed only in winter to offer anti-slip materials at a specific time and place on the road surface. The anti-slip maintenance nowadays uses live contextual data from many different sources [2], including open data sources [3], and decision-making results significantly depend on data availability [4]. A pastime may affect the essential operations of the road network in total. One of them is driving conditions when traffic speed is rapid. The higher the rate, the greater the probability that accidents will occur [5]. As it is known, the road conditions are subject to rapid changes in surface temperature and precipitation sum. The highest fluctuations of the road condition are observed during the winter period; however, the state of the road is also affected by the snow and icing. The road maintenance is performed for specific road sections belonging to a region.

The region in the research is the road network of the Republic of Latvia. This region consists of 55 road monitoring weather stations that are relatively distant from each other. To be able to respond to changes in the environment, monitoring weather stations and cameras operated by different entities are located on road sections near the road surface. Road monitoring weather stations collect raw observations that are processed to be able to make the necessary forecasting for future decisions. For road maintainers, those predictions are crucial to making decisions daily. Road monitoring weather stations and cameras operated by different entities can help in decision-making. The road maintainers controlling smart road signs can give warning messages to drivers at a specific stage of the road network [6]. Missing out information in the time-series of weather stations is unavoidable owing to the full observation of all continuous processes that are almost impossible [7]. Road maintainers need to allocate the resources they are given accurately. One of them is a fleet of specialised trucks that can maintain the right road conditions. Specialised trucks are equipped with an anti-slip material spreader system for the road surface and with snow blades on the front. As it is well known, the cost is very high for road maintenance during the winter months. It is to service the entire road network; it is proportionate and rational to divide the fleet by region. By placing a fleet member in each area that responds to the road service according to the weather forecasters, for example, it is predicted that the snow in that region will be tomorrow. The response to such a forecast is that the fleet member handles the section of the road ahead of the forecast time frame in that particular region. This is where losses occur, as it is often the case that weather forecasts are incorrect and fleet member resources are wasted. For this reason, this article will be able to define the mathematical model of operations research for this case.

The rest of the paper is organised as follows: Section II discusses a literature review, Section III proposes model formulation, and Section IV provides summary and conclusions.

\section{LITERATURE REVIEW}

The literature review focuses on the development of a new mathematical model, by researching existing mathematical models and their formulation principles. The new mathematical model includes forecasting that will be integrated into ERP systems to improve the business processes. As in any literature review, most should be highlighted in the specific field where the relevant keywords are searched for and the topic of interest. In this case, keywords are compiled for the scientific articles in Table I.

TABLE I

LITERATURE REVIEW KEYWORD LIST ON RESEARCH ARTICLES

\begin{tabular}{|l|c|}
\hline Keywords & Research Articles \\
\hline Model Formulation & {$[8]-[13]$} \\
\hline Operations Research Model Formulation & {$[14]-[23]$} \\
\hline Mathematical Model Formulation & {$[24]-[32]$} \\
\hline Linear Programming Model Formulation & {$[33]-[42]$} \\
\hline
\end{tabular}


The model formulation for road maintenance is almost as old as operations research itself; [8] provides a comparison of differences between operations research steps that have changed over centuries. Formulating the problem and implementing the solution remain precisely as they were defined in the beginning; the rest of the steps have changed over time. The coding process has also been changed, and it is easier to implement solution nowadays. In [9], authors demonstrate numerical values of practical empirical model parameters for a given workpiece, which proves that changing the model parameter can affect the achievement of better results, which confirm the operations research theory, i.e., changing settings can experimentally yield better results than the original. In [10], using spectral models proves that the model formulation requires parameter adjustment. In [11], Mixed-integer model formulation is outlined. However, the presentation of disjunctive formulation techniques emphasises that not all problems can be solved by this method. The operations research theory also states that each problem requires its own approach and method and that customisation is required. Moving closer to the problem, [12] combines the need for uncertainty from regional model formulation to obtain accurate results emphasising the need for precision.

When it comes to operations research (OR) model formulation, it is good to know how to use OR for different problem-solving tasks. In [13], author discusses model formulation and algorithms with a detailed problem description and notation also expanding the complexity of model formulation in the routing train case. The paper also addresses the feasibility problem before model formulation that is one of OR tasks to understand where the possible solutions are socalled feasible region that is also applied in mathematical optimisation. In [14], authors aim at minimising the waiting time; however, the problem is formulated as a mixed-integer programming model, the results of which demonstrate significant improvement [15]. In [16], authors show the goal programming model, which is best known in mathematical programming with multiple objectives emphasising another type of model formulation principles. In [17], the improved formulas for problem-solving for the hub are proposed to improve previous results; in other words, the experiment is repeated, and the metrics are improved. In [18], authors represent an economic order quantity (EOQ) model, its formulation and use in specified cases, as well as present a new "sustainable EOQ model". It follows that the models need to be modified for a specific task. In [19], model formulation in a particular way for single machine scheduling to minimizing the maximal lateness on a single machine and minimizing the sum of weighted completion times on a single machine also parallel preemptive machine scheduling. A very detailed example of model formulation is reflected with raised OR objectives. In [20], authors not only show the model formulation but also propose the algorithm that inserts and defines the model as well as runs it. The model formulation and algorithm are about the capacitive batch size problem (CLSP). In [21], with a substantial literature review, authors represent integrality constraints in the model for the level of repair analysis. They state that it is possible to cut costs using this approach. The OR can deal with simple tasks where the use of mathematics is required; one can define and execute, according to specific criteria, a task or goal that has to be achieved within a specified time with specific parameters. However, a closer look at the literature suggests that each case requires an adaptive approach for changing parameters.

The next keyword "Mathematical Model Formulation" is searched for. The OR already offers a way to define mathematical models, but the literature can find its obstacles as well as more accessible paths to more precisely formulate a mathematical model, which is the goal of this article. In [22], authors present the basic principles of formulating a classic 20th-century mathematical model that can be easily perceived and used. In [23], authors discuss that it is necessary to develop a precise mathematical representation for tasks as well as appropriate tools to run the mathematical model. In [24], authors introduce one more mathematical model and solution; however, the model can be applied to a real-world situation and every mathematical model can be improved. In [25], authors provide a case study in strategic-tactical model formulation. The comparison of the model solution and real decisions is used to prove the applicability and usefulness of the strategic-tactical model. The strategic-tactical model makes it easier to understand the expected result after defining the model and implementing it. In [26], authors offer interesting mathematical model formulation that introduces one of the types of mathematical notation associated with colour device calibration. In [27], originally the problem is formulated as a mixed-integer nonlinear program (MINLP); the model obtained can be simplified by the mixed-integer bilinear program (MIBLP), in which the objective function as a continuous variable multiplies only the nonlinearity through precise linearisation. In other words, it is possible to obtain better results from the initial mathematical model to the next simpler model. It is proven once again that the original model could be called an abstract model that will change over time. In [28], authors confirm that the mathematical model formulation changes and will change each time any parameter value changes dynamically. Once they do, a sensitivity analysis is used.

One way of solving an OR problem is to formulate linear programming model formulation that is already derived from mathematical model formulation and can be entered into a computer program that will be able to optimise the given model with given parameters using OR methods. In [29], the task of traveling salesman problems in OR is invented. Accordingly, this problem affects many different parameters that can be computed by a man on paper and with the help of a palace. However, it has to be taken into account that these parameters are predominantly necessary for a person to do this, which is why computer programs are used, which can calculate and retrieve the best solution for the traveling salesman problem according to the OR principles. In this article, integer programming formulation is used for the traveling salesman problem-solving. In [30], authors introduce linear programming formulation to the overall portfolio selection problem. This problem is frequently solved with quadratic or linear 
programming methods, depending on the risk measure used in the objective function. In [31], author demonstrates a useful linear programming model and optimisation algorithm for trigeneration and presents formulation with the help of mixedinteger linear programming, which is also found in [32]. In [33], authors represent a linear programming model to minimise production and purchase costs simultaneously. Comparing the performance shows better results than what was done before using a linear programming model. A similar observation is made in [34], which produces three times better results than initial ones using the integer linear programming model. However, it is emphasised that there is a kind of limitation with two devices. In [35], on the other hand, authors confirm that it is possible to control the prediction of several performance indicators, but it is severely affected. In [36], author points to the linear formulation of hybrid solvers that would be very relevant in the future. This article emphasises the possibility of solving OR problems in different ways because nowadays there are problems that have not existed historically. As society and technologies keep developing, the demand in several fields has changed radically.

The next section defines and formulates a model that will be used for the future research. Based on scientific papers, the mathematical model is explained in detail with all process steps.

\section{MODEL FORMULATION}

Before defining and formulating the model, it is necessary to understand the nature of the problem in order to perceive a big picture better.

\section{A. Problem Description}

The problem with road maintenance is that it is necessary to know if the road condition is satisfactory or nonetheless dangerous during the winter months and at what point the road maintainer should respond. Defining a satisfactory condition for the road surface at a given stage may indicate that the condition of the road is not icy, nor is there any precipitation or forecast of it in the near future. The following sections will explain this problem in a more detailed way.

In this paper, one of road maintenance problems is targeted. As it is known, in winter, the icing on the road surface puts drivers at risk. Moreover, one of the primary tasks of road maintenance is to keep the road section safe. To ensure this security 24 hours a day, the road maintainers need to monitor the condition of the road with their equipment and record historical data in one place. It takes place in the Republic of Latvia with the help of 55 road monitoring weather stations, and their volume increases every year. In order to be able to clear the road section where it is needed during the winter months, Latvian road maintainers are armed with a large number of specialised trucks capable of handling this task. The only difficult predictable task is that these tasks with specialised trucks need to be pointed at a specific time and place to be able to clear the road surface from snow and ice due to the weather. Responsibility for these decisions lies with the administration, which must base its decisions on weather forecasts, weather stations near road surface, and historical data. Good estimates are needed to make more accurate decisions. To be able to understand and draw any conclusions, one must first ask questions or put forward hypotheses.

\section{B. Presenting the Hypotheses}

The road maintenance problem is focused on the following hypotheses to perform optimisation modelling:

1. Hypothesis 1: It is hypothesised that road maintainers need road condition forecasting;

2. Hypothesis 2: Will the mathematical model be able to improve the time before the road section is in a dangerous condition?

It is necessary to define the parameters and variables, where the OR approach will be explained in more detail.

\section{Defining the Parameters and Variables}

The parameters and variables are defined in Table II to construct the optimisation model of the specific road maintenance problem.

TABLE II

TERMINOLOGY DESCRIPTION OF THE PARAMETERS AND VARIABLES

\begin{tabular}{|c|c|}
\hline Denotation & Description \\
\hline$O_{1}, O_{2}, \ldots, O_{n}$ & Index of weather stations \\
\hline$u_{1}, u_{2}, \ldots, u_{n}$ & Index of road surface condition \\
\hline$t_{1}, t_{2}, \ldots, t_{n+1}$ & Observations (time-series points) \\
\hline$M_{o 1}, M_{o 2}, \ldots, M_{o n+1}$ & Weather stations \\
\hline$C_{u 1}, C_{u 2}, \ldots, C_{u n+1}$ & Road surface condition \\
\hline $\begin{array}{l}S_{\text {Mon+1Cun+1 }}, S_{\text {Mon+2Cun+2, }} \\
\ldots, S_{\text {Mon }+n C u n+n}\end{array}$ & $\begin{array}{l}\text { Status of area: } 0 \text { - good, } 1 \text { - normal, } 2 \text { - possible } \\
\text { risk, } 3 \text { - dangerous }\end{array}$ \\
\hline$F$ & $\begin{array}{l}\text { Set of all the targeted road section orders in the } \\
\text { road maintenance problem }\end{array}$ \\
\hline$f$ & Index of road section orders, and $f \in F$ \\
\hline$\omega_{f}^{-}$ & Index of origin of maintenance service order $f$ \\
\hline$\omega_{f}^{+}$ & $\begin{array}{l}\text { Index of destination of maintenance service } \\
\text { order } f\end{array}$ \\
\hline $\operatorname{send}_{f}$ & $\begin{array}{l}\text { Release time of the maintenance service order } f \\
\text { at its origin }\end{array}$ \\
\hline$\left[\operatorname{arrive}_{f}^{-}, \operatorname{arrive}_{f}^{+}\right]$ & $\begin{array}{l}\text { Arrive time-frame window of maintenance } \\
\text { service order } f \text { claimed by road maintainer, } \\
\text { where arrive } e_{f}^{-} \text {and arrive } e_{f}^{+} \text {are separately the } \\
\text { lower bound and upper bound of the time } \\
\text { window }\end{array}$ \\
\hline$R$ & $\begin{array}{l}\text { Road section of the road network of the } \\
\text { Republic of Latvia }\end{array}$ \\
\hline$A$ & Direction of the road network \\
\hline$T$ & Maintenance service set in the network \\
\hline$i, j$ & Parameters of the road section, and $i, j \in R$ \\
\hline$(i, j)$ & $\begin{array}{l}\text { Direction from } i \text { road section to } j \text { road section } \\
(i, j) \in A\end{array}$ \\
\hline$k$ & Maintenance service \\
\hline$q_{i j k}$ & $\begin{array}{l}\text { For maintenance service } k, q_{i j k} \text { is the entire } \\
\text { capacity of a group of specialised truck fleets } \\
\text { that it can provide }\end{array}$ \\
\hline$N_{i j k}$ & $\begin{array}{l}\text { Maintenance costs per specialised truck unit of } \\
\text { maintenance service } \mathrm{k} \text { on the direction }(i, j)\end{array}$ \\
\hline$N_{\text {pen }}$ & Penalty costs per specialised truck unit per hour \\
\hline Denotation & Description \\
\hline$T_{i j}$ & $\begin{array}{l}\text { Maintenance service set on direction }(i, j) \text {, and } \\
T_{i j} \subseteq T\end{array}$ \\
\hline$s$ & $\begin{array}{l}\text { Status of the maintenance services, and } s \in T \text {. } \\
\text { Types of statuses: } 0 \text { - on hold at base, } 1-\text { on } \\
\text { duty, } 2 \text { - returning to base }\end{array}$ \\
\hline 1 & $\begin{array}{l}\text { Distance from maintenance specialised truck } \\
\text { service base to the road section }\end{array}$ \\
\hline
\end{tabular}




\begin{tabular}{|l|l|}
\hline$x_{i j}^{f}$ & $\begin{array}{l}0-1 \text { variable: if the specialised truck of the } \\
\text { maintenance service } f \text { is on duty to a direction } \\
(i, j), x_{i j}^{f}=1 ; \text { otherwise, } x_{i j}^{f}=0\end{array}$ \\
\hline$y_{i}^{f}$ & $\begin{array}{l}\text { Non-negative variable: the arrival time of the } \\
\text { specialised truck of maintenance service order } f \\
\text { at road section } i .\end{array}$ \\
\hline
\end{tabular}

After all of the variables and parameters have been established, the objective of the optimisation - to reduce the investment in the road maintainer problem - can be defined. The model is built on OR basic principles and can change over time, striving for better results.

\section{Establishing the Optimisation Objective}

The objective of the model is to minimise the total generalised costs for accomplishing the specialised truck of the maintenance service from wrong duty orders. The objective function of a linear programming problem is a linear function of the decision variable expressing the objective of the decisionmaker [8].

In this study, the maintenance service order costs in (1) where $(i=1,2, \ldots, n)$ and $(j=1,2, \ldots, n)$ and penalty costs are caused by the early or delayed accomplishment of maintenance service order in (2).

$$
\begin{gathered}
\operatorname{minimize} \sum_{f \in F} \sum_{(i, j) \in A} \sum_{k \in T_{i j}} N_{i j k} \cdot x_{i j k}^{f} \\
+\sum_{f \in F} N_{\text {pen }} \cdot\left[\begin{array}{c}
\left.\max \left\{\operatorname{arrive}_{f}^{-}-y_{\omega_{f}^{+}}^{f}, 0\right\}+\right] \\
\max \left\{y_{\omega_{f}^{+}}^{f}-\operatorname{arrive}_{f}^{+}, 0\right\}
\end{array}\right]
\end{gathered}
$$

\section{E. Formulating the Constraints}

Equation (3) ensures that no more than one specialised truck of the maintenance service operated on a particular destination.

$$
\sum_{k \in T_{i j}} x_{i j k}^{f} \leq 1 \quad \forall f \in F \quad \forall(i, j) \in A
$$

Equation (4) ensures that the specialised truck of each maintenance service order will punctually depart from the origin at the corresponding release time.

$$
y_{\omega_{\bar{f}}^{-}}^{f}=\operatorname{send}_{f} \quad \forall f \in F
$$

Equations (5) and (6) constrain the domains of the two variables according to their definitions.

$$
\begin{gathered}
x_{i j k}^{f} \in\{0,1\} \quad \forall f \in F \quad \forall(i, j) \in A \quad \forall k \in T_{i j} \\
y_{i}^{f} \geq 0 \quad \forall f \in F \quad \forall i \in R
\end{gathered}
$$

Equation (7) where $\alpha$ is the confidence level that is determined by decision-makers subjectively and falls into the range $[0,1]$ :

$$
\left\{\sum_{f \in F} x_{i j k}^{f} \leq q_{i j k}\right\} \geq \alpha \quad \forall(i, j) \in \mathrm{A} \quad \forall k \in T_{i j} .
$$

Non-negativity restriction indicates that all decision variables must take on values equal to or greater than zero. To prove the second hypothesis, it is required to create a forecasting model; however, this article is only for mathematical model formulation. Nonetheless, the prediction model might be similar to equation (8).

$$
\hat{x}_{t+1}=\alpha x_{t}+(1-\alpha) \hat{x}_{t}
$$

In equation (8), $\hat{x}_{t+1}$ one-step forecast and $x_{t}$ observation of historical last forecast data and the last $\hat{x}_{t}$ are the necessary forecasts. The mathematical model needs to be tested through experiments to evaluate what needs to be improved and using real data can also create the constraints needed for an OR approach to make it easier to identify and understand the feasible region. The optimisation concept is represented in equation (9).

$$
x_{t}=\sum_{i=1}^{P} \alpha_{i} y_{t-1}+\sum_{j=1}^{V} \phi_{i} \varepsilon_{t-j}
$$

Equation (9) represents $\varepsilon$ as noise that sometimes will be equal to zero. The alpha and phi parameters can be used to optimise the prediction model. The model will be linked to data that are unevenly distributed across different sources in space and time.

\section{CONCLUSION}

Involved parameters and objects have been defined; the OR approach has been used to achieve the desired mathematical model. The mathematical model will be used in the future to reduce the overall cost of road maintenance service and to provide a relatively good response time for road maintainers.

To prove the first hypothesis, by making and learning the formulation of a mathematical model and its significance, road maintainers need a road condition forecasting. In order to be able to improve the current situation, it is necessary to create a mathematical model and optimise it for better predictions.

It has been proven that a mathematical model will not be able to improve the time before the road section is in a dangerous condition. The mathematical model is a conceptual set of signs in order to understand what the parameters are and defining an objective function to achieve this result. After defining, it is necessary to carry out practical experiments and repeat them in order to be able to compare them before this mathematical model produces better results. According to the OR approach, only after optimisation, the result can be improved, the definition does not give such a result at the first declaration.

\section{REFERENCES}

[1] J. Grabis, Ž. Bondars, J. Kampars, Ē. Dobelis, and A. Zaharčukovs, "Context-Aware Customizable Routing Solution for Fleet Management," in Proceedings of the 19th International Conference on Enterprise Information Systems - Volume 1: ICEIS, Porto, Portugal, 2017, pp. 638-645. https://doi.org/10.5220/0006366006380645

[2] R. S. Pindyck and D. L. Rubinfeld, Econometric Models and Economic Forecasts: Tsp Handbook, vol. 4. Irwin/McGraw-Hill Boston, 1997.

[3] J. Zdravkovic, J. Kampars, and J. Stirna, "Using open data to support organizational capabilities in dynamic business contexts," in Lecture Notes in Business Information Processing, LNBIP, vol. 316, 2018, pp. 28-39. https://doi.org/10.1007/978-3-319-92898-2_3

[4] J. Grabis and V. Minkēviča, "Context-aware multi-objective vehicle routing", in Proceedings of 31st European Conference on Modelling and Simulation, pp. 235-239, 2017. https://doi.org/10.7148/2017-0235 
[5] J. B. Edwards, "Speed adjustment of motorway commuter traffic to inclement weather," Transp. Res. Part F: Traffic Psychol. Behav., vol. 2 , no. $1, \quad$ pp. 1-14, Mar. 1999. https://doi.org/10.1016/S13698478(99)00003-0

[6] Y. Y. Nguwi and A. Z. Kouzani, "Detection and classification of road signs in natural environments," Neural Comput. Appl., vol. 17, no. 3, pp. 265-289, Jun. 2008. https://doi.org/10.1007/s00521-007-0120-z

[7] S. J. Jeffrey, J. O. Carter, K. B. Moodie, and A. R. Beswick, "Using spatial interpolation to construct a comprehensive archive of Australian climate data," Environ. Model. Softw., vol. 16, no. 4, pp. 309-330, 2001. https://doi.org/10.1016/S1364-8152(01)00008-1

[8] T. R. Willemain, "Model Formulation: What Experts Think About and When," Oper. Res., vol. 43, no. 6, pp. 916-932, 1995. https://doi.org/10.1287/opre.43.6.916

[9] H. Y. Feng and C. H. Menq, "The prediction of cutting forces in the ballend milling process-II. Cut geometry analysis and model verification," Int. J. Mach. Tools Manuf., vol. 34, no. 5, pp. 711-719, 1994. https://doi.org/10.1016/0890-6955(94)90053-1

[10] D. Kraay, P. T. Harker, and B. Chen, "Optimal Pacing of Trains in Freight Railroads: Model Formulation and Solution," Oper. Res., vol. 39, no. 1 , pp. 82-99, 1991. https://doi.org/10.1287/opre.39.1.82

[11] R. Daley, C. Girard, J. Henderson, and I. Simmonds, "Short-term forecasting with a multi-level spectralprimitive equation model part II Hemispheric prognoses and verification," Atmosphere, vol. 14, no. 2, pp. 117-135, 1976. https://doi.org/10.1080/00046973.1976.9648406

[12] H. P. Williams and R. G. Jeroslow, "Logic-Based Decision Support: Mixed Integer Model Formulation," The Journal of the Operational Research Society, vol. 41, no. 4. 1990. https://doi.org/10.2307/2583807

[13] D. P. Rowell, "A demonstration of the uncertainty in projections of UK climate change resulting from regional model formulation," Clim. Change, vol. 79, no. 3-4, pp. 243-257, 2006. https://doi.org/10.1007/s10584-006-9100-Z

[14] P. J. Zwaneveld et al., "Routing trains through railway stations: Model formulation and algorithms," Transp. Sci., vol. 30, no. 3, pp. 181-194, 1996. https://doi.org/10.1287/trsc.30.3.181

[15] J. M. Martel and B. Aouni, "Diverse Imprecise Goal Programming Model Formulations," J. Glob. Optim., vol. 12, no. 2, pp. 127-138, 1998.

[16] Y. Shafahi and A. Khani, "A practical model for transfer optimization in a transit network: Model formulations and solutions," Transp. Res. Part A Policy Pract., vol. 44, no. 6, pp. 377-389, 2010. https://doi.org/10.1016/j.tra.2010.03.007

[17] B. Wagner, "Model formulations for hub covering problems," J. Oper. Res. Soc., vol. 59, no. 7, pp. 932-938, 2008. https://doi.org/10.1057/palgrave.jors.2602424

[18] D. Battini, A. Persona, and F. Sgarbossa, "A sustainable EOQ model: Theoretical formulation and applications," Int. J. Prod. Econ., vol. 149, pp. 145-153, 2014. https://doi.org/10.1016/j.ijpe.2013.06.026

[19] H. Yan, Z. Yu, and T. C. E. Cheng, "A strategic model for supply chain design with logical constraints: Formulation and solution," Comput. Oper. Res., vol. 30, no. 14, pp. 2135-2155, 2003. https://doi.org/10.1016/S0305-0548(02)00127-2

[20] J. Blazewicz, M. Dror, and J. Weglarz, "Mathematical programming formulations for machine scheduling: A survey," Eur. J. Oper. Res., vol. 51, no. 3, pp. 283-300, 1991. https://doi.org/10.1016/03772217(91)90304-E

[21] A. Alfieri, P. Brandimarte, and S. D'Orazio, "LP-based heuristics for the capacitated lot-sizing problem: The interaction of model formulation and solution algorithm," Int. J. Prod. Res., vol. 40, no. 2, pp. 441-458, 2002. https://doi.org/10.1080/00207540110081461

[22] R. J. I. Basten, J. M. J. Schutten, and M. C. van der Heijden, "An efficient model formulation for level of repair analysis," Ann. Oper. Res., vol. 172, no. 1, pp. 119-142, 2009. https://doi.org/10.1007/s10479-009-0516-5

[23] D. A. Saville and O. A. Palusinski, "Theory of electrophoretic separations. Part I: Formulation of a mathematical model," AIChE J., vol. 32, no. 2, pp. 207-214, 1986. https://doi.org/10.1002/aic.690320206

[24] M. De Domenico et al., "Mathematical formulation of multilayer networks," Phys. Rev. X3, p. 41022, 2014. https://doi.org/10.1103/PhysRevX.3.041022

[25] D. Kraay, P. T. Harker, and B. Chen, "Optimal Pacing of Trains in Freight Railroads: Model Formulation and Solution," Oper. Res., vol. 39, no. 1, pp. 82-99, 1991. https://doi.org/10.1287/opre.39.1.82
[26] R. Hammami, Y. Frein, and A. B. Hadj-Alouane, "A strategic-tactical model for the supply chain design in the delocalization context: Mathematical formulation and a case study," Int. J. Prod. Econ., vol. 122, no. 1, pp. 351-365, 2009. https://doi.org/10.1016/j.ijpe.2009.06.030

[27] M. J. Vrhel and H. J. Trussell, "Color device calibration: A mathematical formulation," IEEE Trans. Image Process., vol. 8, no. 12, pp. 1796-1806, 1999. https://doi.org/10.1109/83.806624

[28] L. Mockus and G. V. Reklaitis, "Mathematical programming formulation for scheduling of batch operations based on nonuniform time discretization," Comput. Chem. Eng., vol. 21, no. 10, pp. 1147-1156, 1997. https://doi.org/10.1016/S0098-1354(96)00325-0

[29] A. I. Zacharof and A. P. Butler, "Stochastic modelling of landfill leachate and biogas production incorporating waste heterogeneity. Model formulation and uncertainty analysis," Waste Manag., vol. 24, no. 5, pp. 453-462, 2004. https://doi.org/10.1016/j.wasman.2003.09.010

[30] C. E. Miller, R. A. Zemlin, and A. W. Tucker, "Integer Programming Formulation of Traveling Salesman Problems," J. ACM, vol. 7, no. 4, pp. 326-329, 1960. https://doi.org/10.1145/321043.321046

[31] B. K. Stone, "A Linear Programming Formulation of the General Portfolio Selection Problem," J. Financ. Quant. Anal., vol. 8, no. 4, pp. 621-636, 1973. https://doi.org/10.2307/2329828

[32] A. Bellabdaoui and J. Teghem, "A mixed-integer linear programming model for the continuous casting planning," Int. J. Prod. Econ., vol. 104, no. 2, pp. 260-270, 2006. https://doi.org/10.1016/j.ijpe.2004.10.016

[33] S. Benati and R. Rizzi, "A mixed integer linear programming formulation of the optimal mean/value-at-risk portfolio problem," Eur. J. Oper. Res., vol. 176, no. 1, pp. 423-434, 2007. https://doi.org/10.1016/j.ejor.2005.07.020

[34] B. Bilgen and I. Ozkarahan, "A mixed-integer linear programming model for bulk grain blending and shipping," Int. J. Prod. Econ., vol. 107, no. 2, pp. 555-571, 2007. https://doi.org/10.1016/j.ijpe.2006.11.008

[35] K. L. Croxton, B. Gendron, and T. L. Magnanti, "A Comparison of Mixed-Integer Programming Models for Nonconvex Piecewise Linear Cost Minimization Problems," Manage. Sci., vol. 49, no. 9, pp. 1268-1273, 2003. https://doi.org/10.1287/mnsc.49.9.1268.16570

[36] P. Refalo, "Linear formulation of constraint programming models and hybrid solvers," in Lecture Notes in Computer Science (including subseries Lecture Notes in Artificial Intelligence and Lecture Notes in Bioinformatics), vol. 1894, pp. 369-383, 2000. https://doi.org/10.1007/3540-45349-0_27

Jānis Pekša is a Research Assistant of the Faculty of Computer Science and Information Technology at Riga Technical University (Latvia). He received his M.Sc. degree in Information Technology from Riga Technical University. Currently, he is a Doctoral student at the Information Technology Institute of Riga Technical University. His research interests include modularized implementation of autonomous decision-making algorithms in enterprise resource planning systems.

E-mail: Janis.Peksa@ rtu.lv

ORCID iD: https://orcid.org/0000-0003-4125-494X

Kristaps-Pēteris Rubulis is a Research Assistant of the Faculty of Computer Science and Information Technology at Riga Technical University (Latvia). He received his Bachelor's degree in Information Technology from Riga Technical University. Currently, he is a Master's student at the Information Technology Institute of Riga Technical University. His research interests include artificial intelligence application in different fields of study.

E-mail: Kristaps-Peteris.Rubulis@ rtu.lv 